\title{
СИСТЕМА ИНДИКАТОРОВ И ПОКАЗАТЕЛЕЙ ЭКОНОМИЧЕСКОЙ БЕЗОПАСНОСТИ
}

\author{
Левченко Ярослав Васильевич \\ Студент, Кубанский государственный \\ аграрный университет \\ 353380, Россия, Крымск, улииа Западная 38 \\ Мамий Сима Асламбечевна \\ Кандидат экономических наук, доцент \\ Кубанский государственный \\ аграрный университет \\ 350044, Россия, Краснодар, улица Калинина 13
}

\begin{abstract}
Аннотация. Данная работа посвящена исследованию различных индикаторов и показателей экономической безопасности, возможности их использования на теории и практике.

Annotation. This work is devoted to the study of various indicators and indexes of economic security, the possibility of their use in theory and practice.

Ключевые слова. индикаторы, показатели, экономика, экономическая безопастность.

Keywords. Indicators, index, economy, economic security.
\end{abstract}

Тематика экономической безопасности в России берет свое начало с перестроечных времен 1985-1991 гг. Зарождение данного направления во многом было обусловлено острой необходимостью создания принципиально иной системы национальной безопасности в условиях кризисных явлений того времени. В 1994 г. академик Л.И.Абалкин [11] в научно-практическом журнале «Вопросы экономики» открыл дискуссию, направленную на обоснование практических аспектов и механизмов обеспечения национальной безопасности Российской Федерации. В этом же году по поручению Совета Безопасности РФ коллектив ученых под руководством профессора В.К. Сенчагова предложил Концепцию экономической безопасности России [13], где были представлены ключевые аспекты Концепции, подготовлен подробный доклад для ее обоснования.

В 2000 г. Научный совет в составе Совета Безопасности России принял систему показателей и их пороговых значений, состоящую из 19 индикаторов экономической безопасности. Система была разработана и апробирована в Институте экономики РАН. Далее, в 2008 г., в Институте экономики РАН перечень индикаторов был расширен и составил 36 показателей, разделенных на ключевые сферы экономической безопасности. Позже, в 2011 г., был опубликован новый актуализированный перечень индикаторов экономической безопасности для страны [4]. С целью непрерывного контроля экономической безопасности государства были предложены четыре проекции (сферы): социальная сфера, сфера реальной экономики, внешнеэкономическая и денежно-финансовая сферы. Для каждого показателя индивидуально выбирались пороговые уровни, игнорирование которых нарушало устойчивое развитие социально-экономических процессов в государстве и приводило к разрушительным тенденциям в области производства и уровня жизни народонаселения.

Динамический анализ индикаторов позволяет констатировать следующее:

1. Большинство показателей по сей день не достигло порогового уровня. Более того, некоторые индикаторы расположены в существенном отдалении от порогов.

2. Можно отметить отрицательные тенденции удаления от порогового значения показателя доли производства оборудования и машин, а также индикатора соотношения численности людей трудоспособного и пенсионного и возраста.

3. Напротив, ряд исследуемых индикаторов показывает положительную тенденцию. К ним относятся сбор зерна, объем ВВП, среднее расчетное количество детей на одну женщину, средняя продолжительности жизни, безработица, доля жителей с доходами ниже прожиточного уровня и т. д.

4. Ряд анализируемых индикаторов в современных реалиях утратил свою актуальность из-за значительного превышения порогового уровня. Такие показатели включают отношение величины госдолга (внешнего и внутреннего) и долю расходов по его погашению в расходах федерального бюджета.

5. Показатели разнятся по значению стандартного отклонения. Некоторые индикаторы демонстрируют меньшую волатильность и в последнее время стабилизировались. К ним можно отнести коэффициент фондов, объем инвестиций в основной капитал, средства на образование, культуру и здравоохранение. В то же время наблюдаются значительные флуктуации показателей отношения запасов полезных ископаемых к их добыче, среднегодового темпа прироста ВВП, сальдо федерального бюджета и дневных колебаний индекса фондового рынка, что говорит о серьезных диспропорциях и нестационарности экономических процессов, характеризуемых данными показателями. 
В утвержденной в 2017 г. Указом Президента РФ Стратегии экономической безопасности до 2030 года содержится новая система индикаторов экономической безопасности [9]. В предложенной системе особое внимание уделено инновационной составляющей экономики страны. Это прежде всего связано с ключевой ролью данной сферы в решении проблем обеспечения устойчивого развития экономики страны в условиях нестабильных мировых цен на энергоресурсы. Как показано в учебнике [10], все индикаторы Стратегии экономической безопасности целесообразно разделить на пять составляющих проекций. Одним из значительных недостатков Стратегии, на наш взгляд, является отсутствие у индикаторов пороговых значений. В целом, характеризуя новую систему индикаторов, можно констатировать, что, хотя новая система показателей экономической безопасности в целом соответствует современным экономическим реалиям, степень ее баланса и полноты дискуссионна.

В связи с появлением новой Стратегии экономической безопасности Правительство РФ поставило задачу создания Концепции федеральной системы управления рисками в области экономической безопасности (рис. 1). Концепция была обсуждена и одобрена на заседании экспертной сессии симпозиума «Проблемы стратегического управления» 20 февраля 2018 г. в Финансовом университете при Правительстве РФ. Базовые аспекты создания федеральной системы управления рисками подробно описаны в статье [11]. Предполагаемая система мониторинга управления рисками включает сотни тысяч показателей различной иерархии, а их анализ будет проводиться с помощью инструментария имитационного моделирования.

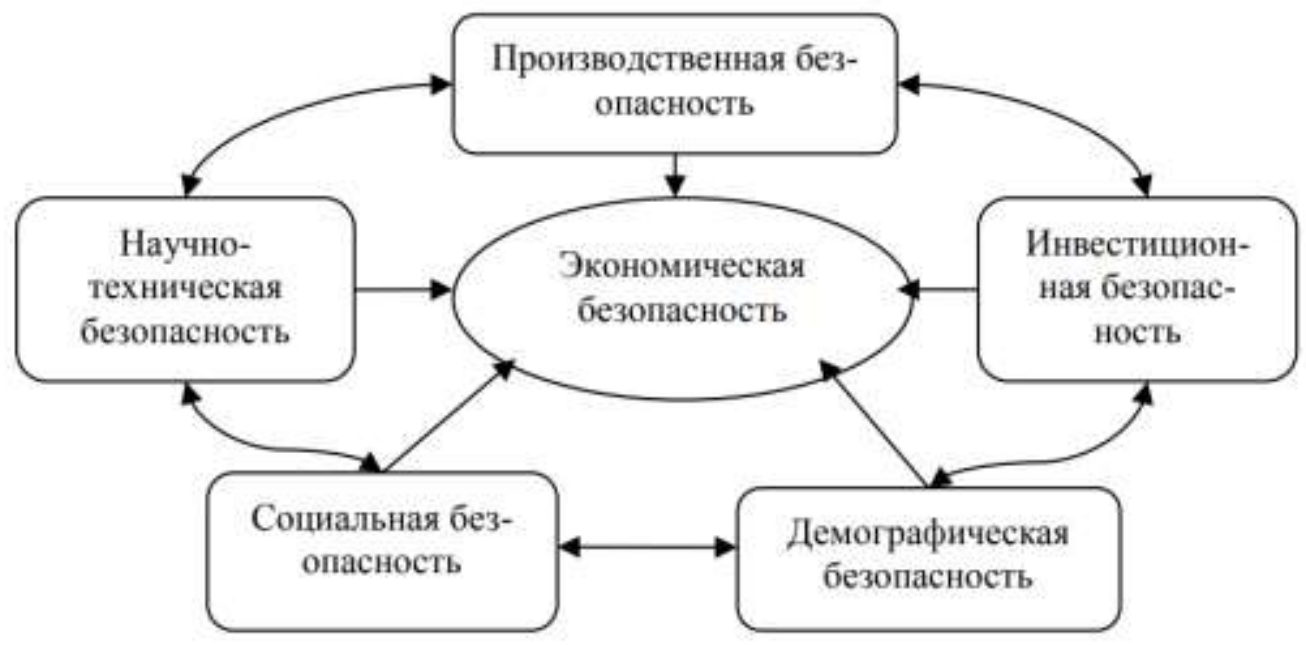

Рисунок 1 - Составляющие экономической безопасности

В основе методологии расчетов пороговых значений во многих случаях лежат экспертные оценки, которые получены в ходе исследований учеными с учетом некоторых среднемировых показателей и тенденций. В ряде случаев в сочетании с экспертными оценками могут использоваться специальные математические методы, позволяющие получить величины пороговых значений в условиях высокой неопределенности исходной информации, а также в силу расхождений в оценках экспертов.

В ходе обеспечения функционирования механизма экономической безопасности важно не только определять изменения, происходящие в экономике, с позиции безопасности, но и диагностировать, вышла ли национальная экономика страны из опасной зоны, в которой угрозы могут вызывать слишком резкие отрицательные последствия и приобретать часто системный характер в форме экономических или финансовых кризисов. С этой целью необходимо видеть границу этих зон, т.е. точно знать, какое значение того или иного количественного показателя-индикатора показывает, что экономика вошла в свою опасную зону.

Важнейшее общее требование к ограниченному перечню значений пороговых экономических показателей безопасности - чтобы он отражал все главные сферы экономики. Угрожающие экономической безопасности факторы формируются и проявляются вначале в одной какой-либо определенной сфере экономики, а затем постепенно переносятся в другие сферы и начинают воздействовать в целом на социально-экономическую ситуацию в стране. Отсюда вытекает это общее требование к перечню пороговых значений — давать возможность использования этих показателей в работе федеральных исполнительных органов, ведающих отдельными экономическими сферами, а также во властных органах субъектов РФ.

Следующее требование к списку пороговых экономических значений безопасности [3], вытекающее из их определения, - получение возможности количественно оценивать состояние определенной сферы экономики. Иными словами, показатель в перечне пороговых индикаторов должен позволять производить 
количественную оценку и соответствовать существующей в стране системе национальной статистики, а также давать возможность сопоставлений с различными странами.

Еще одно важное общее требование к пороговым значениям - необходимость и возможность их использования не только для оценки состояния какой-либо сферы экономики, но и для ее динамики. Это означает, что параметры пороговых экономических значений безопасности должны предоставлять возможность оценки состояния экономического развития. Особо важное требование к значениям индикаторов экономической безопасности - эти показатели должны отражать не второстепенные, а сущностные черты экономических интересов страны и соответствующих им экономических угроз безопасности.

В Государственной стратегии экономической безопасности Российской Федерации [2] определены как количественные, так и качественные параметры состояния экономики (пороговые значения), за пределами которых возникают угрозы экономической безопасности страны.

В их числе:

1. Динамика и структура ВВП, объемы и темпы промышленного производства, структура народного хозяйства (в отраслевом и региональном разрезе) и динамика развития отдельных отраслей, реальные инвестиции;

2. Природно-ресурсный, производственный и научно-технический потенциал;

3. Способность экономического механизма адаптироваться к изменяющимся внешним и внутренним факторам (инфляция, бюджетный дефицит, внешнеэкономические факторальные сдвиги, устойчивость национальной валюты, внешняя и внутренняя задолженность);

4. Качество жизни (ВВП на каждого жителя, размеры безработицы и степень дифференциации доходов, обеспеченность населения материальными благами и жизненно важными услугами, экология).

Для количественной оценки экономической безопасности необходимо придерживаться следующей последовательности:

1. Определение главных направлений деятельности по обеспечению экономической безопасности. При выделении этих обеспечивающих направлений необходимо учитывать все виды существующей экономической деятельности.

2. Определение перечня важнейших показателей экономической безопасности. Этот перечень необходим для того, чтобы регулярно проводился мониторинг с анализом полученных результатов и оценкой отклонений фактических значений от их пороговых уровней.

3. Определение собственно пороговых значений важнейших показателей экономической безопасности. Чтобы определить возможность подобных расчетов необходимо иметь статистически достоверную информацию за достаточно продолжительный соответствующий ретроспективный период, что позволяло бы в случае необходимости вовремя и с минимальными потерями корректировать неверные решения по основным функциональным составляющим.

4. Определение и сводка фактических значений. Это, во-первых, определение фактических значений показателей экономической безопасности, во-вторых, сбор данных об изменении их значений но сравнению с базисным периодом, в-третьих, консолидация полученных данных с помощью единой централизованной информационной системы.

5. Анализ сведенных данных: сопоставление значений полученных фактических данных с их имеющимися пороговыми значениями безопасности, комплексная оценка самих пороговых значений всех индикаторов (показателей), углубленное исследование полученной информации с учетом необходимых взаимосвязей экономических параметров.

6. Выяснение причин расхождения между фактическими и пороговыми значениями экономической безопасности, т.е. определение существующих внешних и внутренних угроз национальной экономике. На данном этапе необходимо определить «слабые места», т.е. бреши в системе экономической безопасности, определить важнейшие угрозы этой системе в соответствии с основными направлениями деятельности объекта экономической безопасности.

7. Создание полномасштабной и многоуровневой системы отслеживания динамики всех основных экономических показателей безопасности государства с применением современных инструментов наблюдения и контроля для регулирования экономических процессов, т.е. внедрение системы комплексного мониторинга.

Первостепенной задачей системы мониторинга безопасности с помощью экономических показателей выступает формирование такой системы информационно-аналитического обеспечения, которая осуществляет выявление тенденций основных экономических показателей безопасности, учет, анализ и прогнозирование изменений в мировой экономике, а также определение рисков и угроз, которые необходимо распределить (риски) или снизить (угрозы).

Мониторинг экономических угроз безопасности с помощью аналитических показателей-индикаторов позволяет обнаружить критические точки, чтобы использовать их в качестве соответствующих пороговых значений. 
С января 2015 года Мониторинг экономической ситуации публиковался в виде аналитических обзоров под общим названием «Оперативный мониторинг экономической ситуации в России. Тенденции и вызовы социально-экономического развития» [14]. Его задачей является отслеживание текущих тенденций и изменений в экономике России.

Чтобы осуществлять защитную функцию в сфере национальной экономики, государству необходимо отслеживать существующую между безопасной и опасной зонами границу в динамике различных сфер экономической деятельности, главным образом, путем фиксации и соблюдения порогов показателейиндикаторов.

Таким образом, должны быть разработаны качественные и количественные параметры (пороговые значения), выход за пределы которых вызывает угрозу экономической безопасности страны.

В экономической литературе рекомендуют различные пороговые значения показателей-индикаторов экономической безопасности государства. Так, в 2001 г. И. Я. Богданов предложил подходы к формированию системы индикаторов экономической безопасности и оценил вероятные социально- политические и экономические последствия (табл. 1).

Таблица 1

Предельно критические значения (границы безопасности) развития российского общества на примере экономических отношений

\begin{tabular}{|c|c|c|c|c|}
\hline $\begin{array}{l}\text { № } \\
\Pi / \Pi \\
\end{array}$ & Название показателя & $\begin{array}{c}\text { Предельно } \\
\text { критическое } \\
\text { значение в } \\
\text { мировой практике }\end{array}$ & Источник данных & $\begin{array}{c}\text { Вероятные социально- } \\
\text { политические и } \\
\text { экономические последствия }\end{array}$ \\
\hline 1 & Уровень падения ВВП & $30-40 \%$ & $\begin{array}{c}\text { Падение ВВП в США в } \\
\text { период Великой депрессии }\end{array}$ & $\begin{array}{c}\text { Деиндустриализация } \\
\text { экономики } \\
\end{array}$ \\
\hline 2 & $\begin{array}{c}\text { Доля импортных продуктов } \\
\text { питания }\end{array}$ & $30 \%$ & $\begin{array}{c}\text { Данные Международной } \\
\text { федерации } \\
\text { агропроизводителей }\end{array}$ & $\begin{array}{c}\text { Стратегическая зависимость } \\
\text { жизнедеятельности страны } \\
\text { от импорта }\end{array}$ \\
\hline 3 & $\begin{array}{c}\text { Доля в экспорте продукции } \\
\text { обрабатывающей } \\
\text { промышленности } \\
\end{array}$ & $40 \%$ & $\begin{array}{c}\text { Обобщенное значение } \\
\text { показателей развитых } \\
\text { стран } \\
\end{array}$ & $\begin{array}{c}\text { Колониально- сырьевая } \\
\text { структура экономики }\end{array}$ \\
\hline 4 & $\begin{array}{c}\text { Доля в экспорте } \\
\text { высокотехнологичной } \\
\text { продукции }\end{array}$ & $10-15 \%$ & $\begin{array}{c}\text { Обобщенное значение } \\
\text { показателей развитых } \\
\text { стран }\end{array}$ & $\begin{array}{c}\text { Технологическое отставание } \\
\text { экономики }\end{array}$ \\
\hline 5 & $\begin{array}{c}\text { Доля государственных } \\
\text { ассигнований на науку от } \\
\text { ВВП }\end{array}$ & $2 \%$ & $\begin{array}{c}\text { «Независимая газета». } \\
\text { 1995. } 25 \text { фев. }\end{array}$ & $\begin{array}{c}\text { Разрушение } \\
\text { интеллектуального } \\
\text { потенциала }\end{array}$ \\
\hline
\end{tabular}

Важнейшей проблемой характеристики экономической безопасности на макроуровне является определение ее основных критериев и показателей. Основой формирования этих показателей является тесная взаимосвязь понятия безопасности с категорией риска.

Таким образом, для проектирования системы минимизации рисков как элемента обеспечения экономической безопасности необходимо последовательно решить несколько задач. На первом этапе важной 
является задача отбора наиболее значимых с экономической точки зрения показателей экономической безопасности, определения и обоснования пороговых значений отобранных показателей. В вышеописанном материале предложен действующий в нашей стране подход к решению этой задачи. Полученная совокупность индикаторов экономической безопасности является частью модели системной динамики для проектирования системы минимизации рисков.

При формировании модели системной динамики возможно увеличение числа показателей экономической безопасности. Допустимо также формирование единого, обобщенного параметра оптимизации как функции ценности, в которой будут отражены все показатели экономической безопасности.

\section{Список использованных источников}

1. Указ Президента РФ от 13 мая 2017 г. N 208 "О Стратегии экономической безопасности Российской Федерации на период до 2030 года" [Электронный ресурс]. - Режим доступа: http://www.consultant.ru/document/cons_doc_LAW_216629/

2. Указ Президента Российской Федерации от 29.04.1996 №608 «О государственной стратегии экономической безопасности Российской Федерации» [Электронный ресурс]. - Режим доступа: http://kremlin.ru/acts/bank/9261

3. Указ Президента Российской Федерации от 17.12.1997 №1300 «Об удтверждении Концепции национальной безопасности Российской Федерации» [Электронный ресурс]. - Режим доступа: http://www.kremlin.ru/acts/bank/11782

4. «Система индикаторов экономической безопасности муниципалитета как составной элемент многоуровневой системы экономической безопасности» [Электронный ресурс]. - Режим доступа: https://cyberleninka.ru/article/n/sistema-indikatorov-ekonomicheskoy-bezopasnosti-munitsipaliteta-kak-sostavnoyelement-mnogourovnevoy-sistemy-ekonomicheskoy

5. Андреев А. В., Основы региональной экономики Российской Федерации [Текст]: учебник / А. В. Андреев. - М.:БЕК, 2016.-785 с.

6. Бочков А. А. Совершенствование региональной безопасности [Электронный ресурс]/ А. А. Бочков, Д. К. Куренок // Труды Кубанского государственного аграрного университета.- Краснодар.-2015.- №2.- С. 8-15.Режим доступа: http://kgau-works.kubsau.ru/issue/2015-22

7. Гаджиев Н. Г. Экономическая безопасность России на современном этапе социально-экономического развития общества [Текст] учебное пособие / Н. Г. Гаджиев, С. А. Коноваленко, О. В. Киселева, О. В. Скрипкина, М. Н. Трофимов - М.: Инфра-М, 2021.-233 с.

8. Кириллов А. В. Экономика [Текст]: учебное пособие /А. В. Кириллов, Н. А. Масич, О. К. Карамышева и др.-М.: Высшая школа, 2017.- 648 с.

9. Показатели для оценки состояния экономической безопасности России [Электронный ресурс]. - Режим доступа: https://rosstat.gov.ru/new_site/pok-besopasn.htm (Дата обращения 17.12.2020)

10. Шимко Н. В. Основы экономики [Текст]: учебник / Н. В. Шимко. - М.: Юрайт, 2018.-630 с.

11. Абалкин Л. И. Экономическая безопасность России: угрозы и их отражение: статья /Вопросы экономики/ [Электронный ресурс]. - Режим доступа: https://www.elibrary.ru/item.asp?id=21823790

12. Легасов В. А. Проблемы безопасного развития техносферы /Коммунсит/ [Электронный ресурс]. Режим доступа: http://riskprom.ru/load/16-1-0-69

13. В. К. Сенчагов Концепция экономической безопасности России /По материалам доклада на научнопрактической конференции «Международная безопасность России в условиях глобализации/ [Электронный pecypc]. - Режим доступа:https://cyberleninka.ru/article/n/ekonomicheskaya-bezopasnost-rossii-4/viewer

14. «Оперативный мониторинг экономической ситуации в России. Тенденции и вызовы социальноэкономического развития» [Электронный ресурс]. - Режим доступа: https://www.ranepa.ru/nauka-ikonsalting/strategii-i-doklady/monitoring-ekonomicheskoj-situatsii/ 